\title{
CD28 ligation induces transplantation tolerance by IFN- $\gamma$-dependent depletion of $T$ cells that recognize alloantigens
}

\author{
Xue-Zhong Yu,1,2 Michael H. Albert, ${ }^{1}$ Paul J. Martin,1,2 and Claudio Anasetti1,2 \\ ${ }^{1}$ Human Immunogenetics Program, Clinical Research Division, Fred Hutchinson Cancer Research Center, Seattle, Washington, USA. \\ 2Department of Medicine, University of Washington, Seattle, Washington, USA.
}

\begin{abstract}
Administration of an agonistic anti-CD28 $\mathrm{mAb}$ paradoxically inhibits donor $\mathrm{T}$ cell expansion and prevents graft-versus-host disease (GVHD) in mice. Here we examined the mechanism of anti-CD28-mediated immunosuppression and found that anti-CD28 $\mathrm{mAb}$ activated, rather than blocked, CD28-mediated signaling in vivo. Anti-CD28 treatment prevented GVHD by selectively depleting alloantigen-activated donor $T$ cells through apoptosis but spared the $T$ cells that did not recognize recipient alloantigens. Overexpression of $B c l-x_{L}$ did not protect $T$ cells from depletion and did not affect GVHD prevention after anti-CD28 treatment. Depletion of activated T cells mediated through CD28 did not depend on the expression of death receptors Fas and TNF receptors type I and II, but both the depletion of activated T cells and the suppressive effect of anti-CD28 $\mathrm{mAb}$ on GVHD lethality required donor-derived IFN- $\gamma$ production. This study demonstrates that agonistic Ab's specific for the CD28 costimulatory molecule may be used as novel therapeutic agents to abrogate pathogenic $T$ cell responses by selective depletion of activated $T$ cells.
\end{abstract}

\section{Introduction}

Costimulation is required for a productive immune response after $\mathrm{T}$ cell receptor (TCR) engagement by the MHC/peptide complex (1). The best-characterized and most potent costimulatory molecule expressed on $\mathrm{T}$ cells is CD28, a 44-kDa homodimeric glycoprotein that binds to B7-1 (CD80) and B7-2 (CD86) on APCs $(2,3)$. CD28 costimulation increases transcription and stability of mRNA encoding IL-2 (4). CD28 costimulation also increases the expression of the antiapoptotic protein, $\mathrm{Bcl}-\mathrm{x}_{\mathrm{L}}$, thereby sustaining proliferation of activated T cells (5). CD28 engagement promotes the formation of an immunological synapse (6) and lowers the threshold of TCR signaling required for effective cytokine production or proliferation $(7,8)$. Previous studies by us and others indicated that CD28 plays an important role in $\mathrm{T}$ cell activation and in the pathogenesis of graft-versus-host disease (GVHD) $(9,10)$.

Although CD28 functions predominantly as a positive regulator for $\mathrm{T}$ cell activation, several lines of evidence indicate that CD28 can also contribute to negative selection of peripheral T cells. CD28 signals that contribute to clonal expansion and effector function also rendered $\mathrm{T}$ cells more susceptible to activation-induced cell death (AICD) (11). Absence of CD28 confers resistance to AICD of T cells after stimulation with superantigen (12). In the clinic, CD28-null human $\mathrm{T}$ cells show resistance to apoptosis in patients with systemic lupus erythematosus (13), rheumatoid arthritis (14), or multiple sclerosis (15). These observations support the concept that the CD28 signal may facilitate peripheral $\mathrm{T}$ cell apoptosis. Furthermore, direct evidence has emerged from recent studies showing that when T cells are engaged with a strong TCR signal,

Nonstandard abbreviations used: activation-induced cell death (AICD); C57BL/6 (B6); graft-versus-host disease (GVHD); murine CD28 (mCD28); phycoerythrin (PE); RNase protection assay (RPA); staphylococcal enterotoxin A (SEA); T cell receptor (TCR)

Conflict of interest: The authors have declared that no conflict of interest exists.

Citation for this article: J. Clin. Invest. 113:1624-1630 (2004).

doi:10.1172/JCI200420940. the CD28 signal reduces T cell expansion, increases apoptosis, and facilitates tolerance $(16,17)$.

CD28-specific Ab (37.51) has been used in experimental models to mimic the natural ligands and provide costimulatory signals to $\mathrm{T}$ cells, thus preventing $\mathrm{T}$ cell anergy in vitro (2). In vivo, however, the same CD28-specific Ab inhibited T cell expansion and cytokine production after stimulation with superantigen (18) or peptide antigen (19). We found that anti-CD28 mAb prevents GVHD in mice (20), and Dengler et al. observed that treatment with antiCD28 mAb prolongs allograft survival in rats (21). Blockade and internalization of CD28 were assumed to contribute to these effects of anti-CD28 treatment in vivo. In this study, we provide direct evidence that anti-CD28 is agonistic in vivo and produces immunosuppression by depleting $\mathrm{T}$ cells activated by alloantigens through an IFN- $\gamma$-dependent mechanism.

\section{Results}

Anti-CD28 does not block interaction between B7 and CD28. Administration of anti-CD28 mAb 37.51 inhibits donor $\mathrm{T}$ cell expansion and prevents GVHD in mice (20). A possible explanation is that this $\mathrm{mAb}$ may block the interaction between $\mathrm{B} 7$ and CD28 in vivo. To test this hypothesis, we measured whether anti-CD28 mAb 37.51 can inhibit the binding of murine CD28 fusion protein with human IgG1 (mCD28-Ig) to activated B cells that express B7 but not CD28 (Figure 1). The result showed that CD28-Ig bound to activated $\mathrm{B}$ cells almost equally well, regardless of preincubation with anti$\mathrm{CD} 28 \mathrm{mAb}$ (Figure 1B). Furthermore, anti-CD28 mAb can bind to activated $B$ cells that are precoated with CD28-Ig, but not otherwise (Figure 1A). Therefore, we conclude that anti-CD28 mAb 37.51 and B7 bind to different epitopes of the CD28 extracellular domain.

Anti-CD28 mAb provides $T$ cell costimulation in vivo. To determine whether anti-CD28 mAb provides T cell costimulation in vivo, DO11.10 TCR transgenic mice were injected with antigenic or control peptide plus anti-CD28 or control Ab. Cytokine mRNA levels were measured to evaluate $\mathrm{T}$ cell activation in the spleen. Stimu- 
A

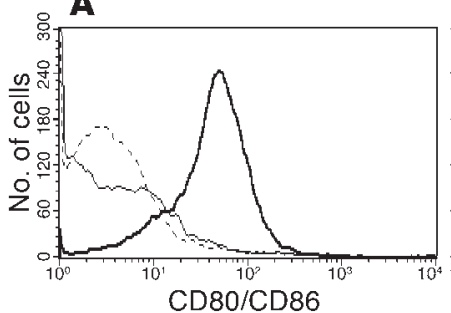

B

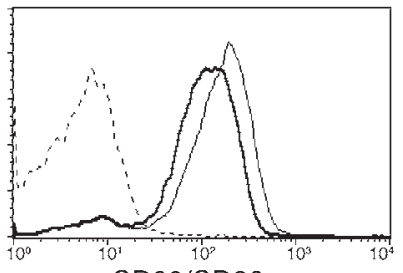

Figure 1

Anti-CD28 mAb and B7 bind to different epitopes of CD28. LPS-activated $B$ cells were incubated with hamster anti-mouse $C D 28 \mathrm{mAb}$ alone (dotted lines), mCD28-Ig alone (thin lines), or mCD28-Ig plus anti-CD28 $\mathrm{mAb}$ (thick lines). Cells were washed and then incubated with PE-conjugated goat anti-hamster IgG to detect anti-CD28 mAb (A) or with PEconjugated goat anti-human IgG to detect mCD28-lg (B).

lation with OVA peptide induced cytokine production, whereas stimulation with control peptide did not. The levels of cytokine mRNA were much lower after OVA stimulation in CD28-deficient mice than in WT mice (Figure 2A, lanes 3 and 6), indicating that the $\mathrm{CD} 28$ signal enhances cytokine production in response to antigen. In contrast, the levels of IL-2, IL-6, IL-10, IL-15, and IFN- $\gamma$ mRNA were higher after stimulation with OVA plus anti-CD28 $\mathrm{mAb}$ as compared with stimulation with OVA alone (Figure 2A, lanes 3 and 4). These results indicate that anti-CD28 $\mathrm{mAb}$ increases, rather than blocks, $\mathrm{T}$ cell activation in vivo.

In further experiments, CD80/CD86-deficient mice were injected with anti-CD28 mAb, staphylococcal enterotoxin A (SEA), or both in combination under conditions where CD28 ligands are absent. Stimulation with SEA plus anti-CD28 mAb induced intracellular IL-2 expression in a significantly higher proportion of TCR V $\beta 3$ or V $\beta 11$ cells $(P<0.05$, Figure $2 \mathrm{~B})$ and IL-2 secreted in the serum $(P<0.01$, Figure $2 \mathrm{C})$ than did stimulation with anti-CD28 $\mathrm{mAb}$ or SEA alone. These results provide direct evidence that this anti$\mathrm{CD} 28 \mathrm{mAb}$ has agonistic effects in vivo.

Treatment with anti-CD28 $\mathrm{mAb}$ is effective in preventing GVHD induced by polyclonal $C D 4$ and $C D 8$ cells. To test whether anti-CD28 treatment would prevent GVHD mediated by CD4 and CD8 T cells, a well-estab-

\section{Figure 2}

Anti-CD28 mAb provides costimulatory signals to T cells in vivo. (A) Anti-CD28 mAb increases cytokine mRNA levels in activated T cells in vivo. DO11.10 WT (lanes 1-4) or CD28-deficient (lanes 5 and 6) mice were injected with control $\mathrm{mAb}$ plus control peptide (lanes 1 and 5 ), antiCD28 mAb plus control peptide (lane 2), control mAb plus OVA peptide (lanes 3 and 6), or anti-CD28 mAb plus OVA peptide (lane 4). One hour after injection, spleens were harvested, and RPA was used to measure cytokine mRNA levels. The lower portion of the gel was exposed to the $x$-ray film for a much shorter period of time than was the upper portion in order to produce bands of similar intensity for L32 and GAPDH as for other probes. Each band represents one of two mice in the group. Results from one of three representative experiments are shown. (B) Anti-CD28 mAb increases IL-2 expression among activated T cells in vivo. B6 CD80/CD86-deficient mice were injected intravenously with $100 \mu \mathrm{g}$ of anti-CD28 mAb, $10 \mu \mathrm{g} / \mathrm{mouse}$ of SEA, or both in combination. Splenocytes were stained for surface expression of CD4 and TCR $\mathrm{V} \beta 3,11$ and for intracellular expression of IL-2. The data shown are intracellular IL-2 expression on gated CD4+/TCR V $33,1^{+} 1^{+}$(SEA-reactive) cells. (C) Anti-CD28 mAb increases IL-2 production in the serum. Data are shown as averages of two mice in each group with error bars indicating $1 \mathrm{SD}$. Results represent one of two replicate experiments. lished murine GVHD model with C57BL/6 (B6) (H2 ${ }^{\mathrm{b}}$ ) donors and $\mathrm{B} 10 . \mathrm{BR}\left(\mathrm{H} 2^{\mathrm{k}}\right)$ recipients was used. Lethally irradiated B10.BR mice were transplanted with bone marrow plus supplemental splenocytes from WT B6 donors, and B10.BR recipients were treated with antiCD28 mAb or irrelevant hamster IgG (Figure 3A). Anti-CD28 treatment significantly reduced GVHD lethality compared with control treatment $(P<0.0001)$. We also tested the effects of CD28 ligand blockade with CTLA4-Ig on GVHD in the same model system. Treatment with CTLA4-Ig prolonged survival as compared with control treatment $(P<0.001)$, but none of the recipients survived long-term (Figure 3B). Collectively, these results suggest that agonistic signals resulting from binding of anti-CD28 mAb produce immunosuppression by a mechanism distinct from neutralization of CD28.

Anti-CD28 mAb depletes antigen-activated CD8 cells in vivo. To assess the fate of antigen-specific CD8 cells in vivo after anti-CD28 treatment, $\mathrm{CD}^{+}$cells from $\mathrm{B} 6$ donors were transplanted into irradiated syngeneic $\mathrm{B} 6$ or allogeneic $\mathrm{BALB} / \mathrm{c}$ recipients, and recipients were treated with anti-CD28 or control $\mathrm{Ab}$. In syngeneic $\mathrm{B} 6$ recipients, donor cells $\left(\mathrm{CD}^{+} / \mathrm{CFSE}^{+}\right)$divided slowly, and the initial rate of proliferation was not affected by CD28 expression or by administration of anti-CD28 mAb in the absence of alloantigen. Furthermore, WT donor cells were not appreciably depleted by anti-CD28 treatment, and few apoptotic $\mathrm{CD} 8^{+}$cells could be detected among these three groups (Figure $4 \mathrm{~A}$ ). In allogeneic BALB/c recipients, both WT and CD28-deficient donor $\left(\mathrm{H} 2^{\mathrm{b}+} / \mathrm{CD} 8^{+}\right)$cells divided rapidly and expanded extensively, but there was a dramatic difference in the percentage of WT cells with or without anti-CD28 treatment. Anti-CD28 treatment did not block $\mathrm{CD}^{+}$cell division but depleted $\mathrm{CD}^{+}$cells that were rapidly dividing while sparing those that were dividing slowly or not at all (Figure 4B). CD8 ${ }^{+}$cells remaining after treatment had much higher levels of apoptosis as

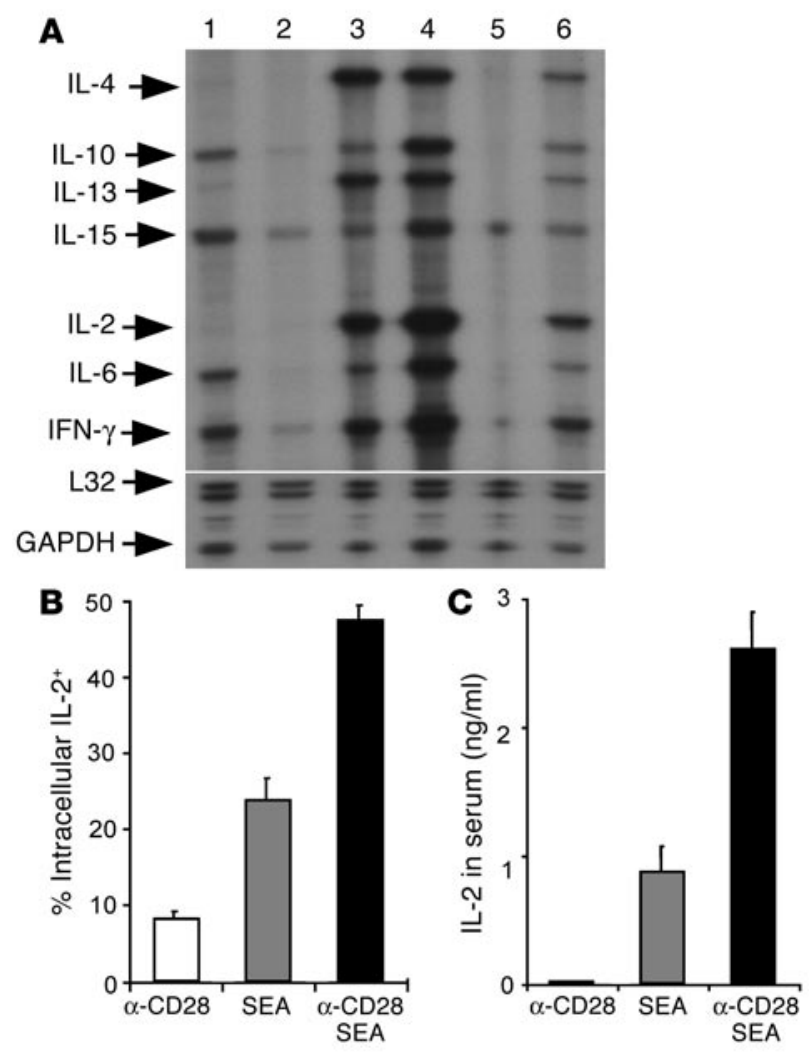




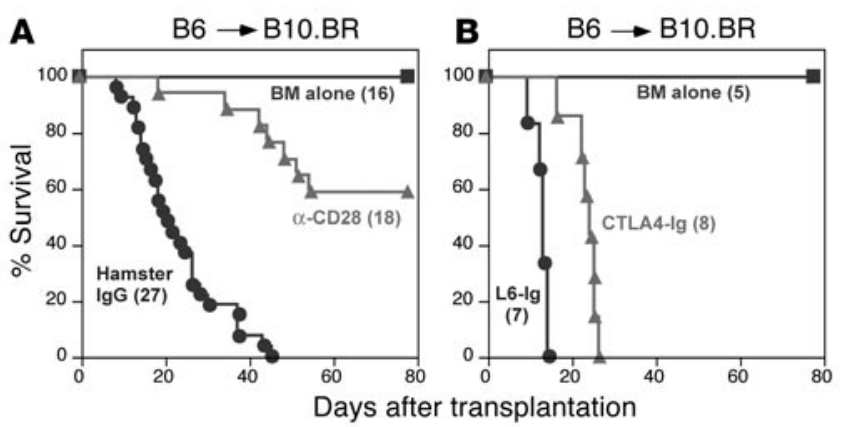

compared with WT or CD28-deficient cells derived from untreated mice. These results indicate that the anti-CD28 mAb depletes alloantigen-activated CD8 cells through apoptosis in vivo.

Anti-CD28 mAb also depletes antigen-activated CD4 cells. To test whether anti-CD28 mAb can also deplete antigen-activated CD4 ${ }^{+}$ cells, purified Thy $1.2^{+}$cells were injected into irradiated syngeneic $\mathrm{B} 6$ or allogeneic BALB/c mice, and recipients were sacrificed after 88 hours. In $\mathrm{B} 6$ recipients, anti-CD28 treatment had no effect on homeostatic proliferation of donor $\mathrm{CD}^{+}$or $\mathrm{CD}^{+}$cells and did not deplete donor cells in the absence of alloantigen (Table 1). In allogeneic $\mathrm{BALB} / \mathrm{c}$ recipients, the percentage and absolute numbers

\section{Figure 3}

Anti-CD28 mAb prevents GVHD lethality. Lethally irradiated B10.BR mice were transplanted with $T$ cell-depleted bone marrow plus supplemental splenocytes from WT B6 donors. B10.BR recipients were treated with anti-CD28 mAb or hamster $\lg G(\mathbf{A})$ or with CTLA4-Ig or L6-Ig (B), each at $100 \mu \mathrm{g} /$ mouse every other day for a total of eight doses. The number of mice in each group is indicated in parentheses, and the data were pooled from three replicate experiments for $\mathbf{A}$ and one experiment for B. BM, bone marrow.

of $\mathrm{CD}^{+}\left(\mathrm{CD}^{-} / \mathrm{H}_{2} \mathrm{~K}^{\mathrm{b}+}\right)$ and $\mathrm{CD}^{+}\left(\mathrm{CD}^{+} / \mathrm{H} 2 \mathrm{~K}^{\mathrm{b}+}\right)$ donor cells were decreased after anti-CD28 treatment (Table 1). CFSE profiles indicate that the proportion of rapidly dividing cells decreased while the proportion of slowly dividing and quiescent cells increased in the donor $\mathrm{CD}^{+}$and $\mathrm{CD}^{+}$populations after anti-CD28 treatment (Figure 5). Similar results were obtained when the same measurements were made at earlier time points after cell transfer (data not shown). These results demonstrate that anti-CD28 treatment can selectively deplete $\mathrm{CD}^{+}$and $\mathrm{CD}^{+} \mathrm{T}$ cells that recognize alloantigens in vivo.

$B c l-x_{L}$ does not protect $T$ cells from depletion by anti-CD28 $\mathrm{mAb}$ in vivo. An important function of CD28 costimulation is to enhance expression of $\mathrm{Bcl}-\mathrm{x}_{\mathrm{L}}$ and thus promote $\mathrm{T}$ cell survival (5). In our study we found that engagement with an agonistic anti-CD28 $\mathrm{mAb}$ paradoxically depleted alloreactive $\mathrm{T}$ cells through apoptosis. To assess
A Syngeneic B6 recipient

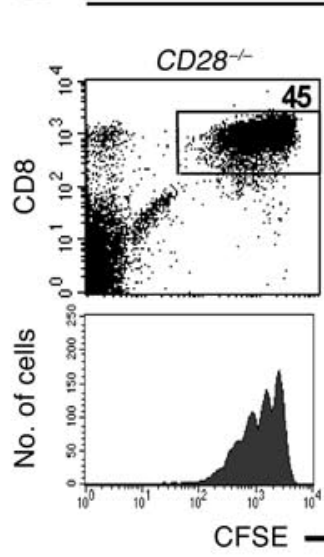

\section{Syngeneic B6 recipient}
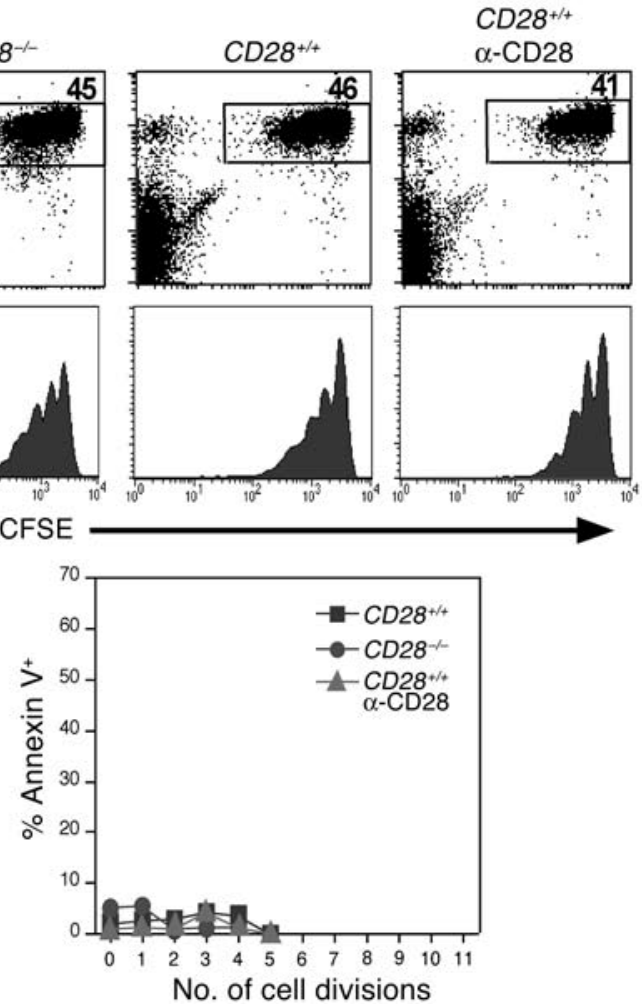

B Allogeneic BALB/c recipient
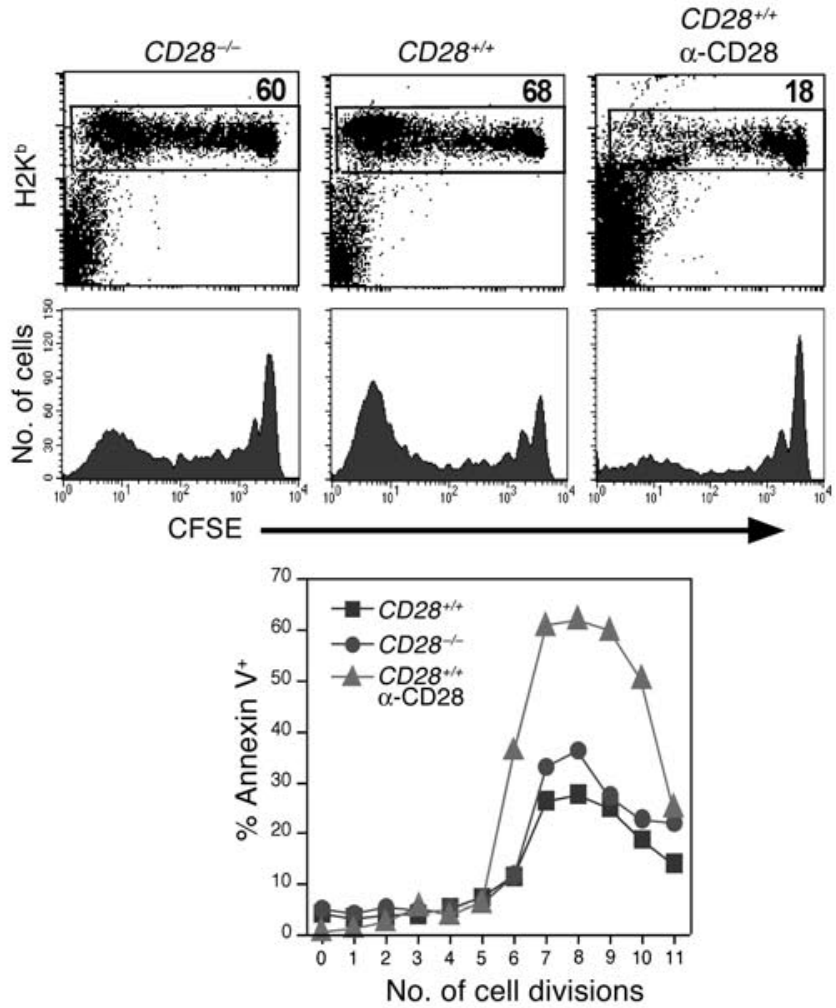

Figure 4

Anti-CD28 mAb depletes donor CD8 cells in allogeneic recipients but not in syngeneic recipients. CFSE-labeled CD8 ${ }^{+}$cells from WT or CD28-deficient B6 donors were transplanted into irradiated (1,000 cGy) B6 (A) or BALB/c (B) recipients. Some recipients were also treated with anti-CD28 mAb at $100 \mu \mathrm{g} /$ mouse on days 0 and 2. Recipient splenocytes were tested at 84 hours after the transplant, and cells were pooled from three mice in each group. $\mathrm{CD}^{+} / \mathrm{CFSE}^{+}$cells were identified as donor cells in $\mathrm{B} 6$ recipients, while $\mathrm{H}_{2} \mathrm{~K}^{\mathrm{b}+}$ cells were identified as donor cells in $\mathrm{BALB} / \mathrm{c}$ recipients. The numbers in the upper panels are the percentages of donor cells in the individual gate, the middle panels show the CSFE profile on gated donor cells, and the lower panels show the percentage of annexin V-positive cells at each cell division. Results represent one of two replicate experiments. 
Table 1

Anti-CD28 treatment depletes both CD4+ and CD8+ donor cells in allogeneic recipients

\begin{tabular}{lcccccccc} 
& \multicolumn{2}{c}{$\begin{array}{c}\text { Syngeneic B6 recipients } \\
\text { CD4+ }\end{array}$} & \multicolumn{2}{c}{$\begin{array}{c}\text { Allogeneic B6 recipients } \\
\text { CD8 }^{+}\end{array}$} & \multicolumn{2}{c}{ CD4 $^{+}$} & CD8 $^{+}$ \\
& Ctrl & CD28 & Ctrl & CD28 & Ctrl & CD28 & Ctrl $^{\text {CD28 }}$ \\
Percentage $^{\mathrm{A}}$ & 9 & 10 & 10 & 10 & 53 & 5 & 14 & 3 \\
Number $^{\mathrm{B}}$ & 15 & 18 & 17 & 18 & 580 & 8 & 150 & 5
\end{tabular}

APercentage of donor cells in recipient spleens at 88 hours after transplantation. ${ }^{B}$ Number of donor cells in recipient spleens in thousands. Ctrl, isotype control Ab; CD28, anti-CD28 mAb.

the role of $\mathrm{Bcl}-\mathrm{x}_{\mathrm{L}}$ in $\mathrm{T}$ cell depletion mediated by anti-CD28 $\mathrm{mAb}$ in vivo, $\mathrm{T}$ cells were isolated from $\mathrm{WT}$ or $\mathrm{Bcl}-\mathrm{x}_{\mathrm{L}}$ transgenic $\mathrm{B} 6$ mice and transferred into irradiated allogeneic $B A L B / c$ recipients. The numbers of CD4 and CD8 donor cells were dramatically reduced in the recipient spleens after anti-CD28 treatment, independent of the level of Bcl- $x_{\mathrm{L}}$ expression (Figure 6A).

We then examined whether overexpression of $\mathrm{Bcl}-\mathrm{x}_{\mathrm{L}}$ can reverse the effect of anti-CD28 treatment on the prevention of GVHD in a well-established murine GVHD model with $\mathrm{B} 6\left(\mathrm{H} 2^{\mathrm{b}}\right)$ donors and bm12 $\left(\mathrm{H} 2^{\mathrm{bm} 12}\right)$ recipients. Lethal acute GVHD was readily induced by $\mathrm{T}$ cells from either WT or Bcl- $\mathrm{x}_{\mathrm{L}}$ transgenic donors. Furthermore, GVHD lethality induced by either type of donor T cells was equally prevented by treatment with anti-CD28 mAb $(P>0.1$, Figure $6 \mathrm{~B})$. The results from these experiments indicate that $\mathrm{Bcl}-\mathrm{x}_{\mathrm{L}}$ cannot protect activated $\mathrm{T}$ cells from death induced by anti-CD28 $\mathrm{mAb}$ in vivo.

Death receptors are not required for $T$ cell depletion caused by anti-CD28 therapy. CD28 engagement with an agonistic mAb 37.51 enhances T cell activation and depletes antigen-activated $\mathrm{T}$ cells through apoptosis, and $\mathrm{T}$ cell apoptosis in vitro depends primarily on death receptors. We therefore expected that death receptor signaling would be required for $\mathrm{T}$ cell depletion by anti-CD28 mAb. To test this hypothesis we compared the susceptibility of T cells from WT donors or Fas, TNF p55, and 75 receptor-deficient donors to anti-CD28-mediated depletion. We found that, regardless of Fas and TNF receptor expression, $\mathrm{CD}^{+}$ and $\mathrm{CD}^{+} \mathrm{T}$ cells were susceptible to in vivo depletion by anti-CD28 treatment (Figure 7), suggesting that Fas and TNF receptors are not required for $\mathrm{T}$ cell depletion in this system. We could not examine the role of these death receptors in the GVHD prevention mediated by anti-CD28 mAb, since T cells deficient for TNF receptors fail to induce GVHD (data not shown and ref. 22).

IFN- $\gamma$ is required for Tcell depletion and prevention of GVHD by anti-CD28 $m A b$. IFN- $\gamma$ inhibits $T$ cell expansion and promotes apoptosis of antigen-activated T cells (23-25) and plays a critical role in the induction of $\mathrm{T}$ cell tolerance in transplantation $(26,27)$. We therefore examined the role of IFN- $\gamma$ in T cell depletion by anti-CD28 mAb. Splenocytes from B6 WT or $I F N-\gamma^{-/-}$mice $\left(\mathrm{H}^{\mathrm{b}}\right)$ were transferred into irradiated allogeneic B10.BR $\left(\mathrm{H} 2^{\mathrm{k}}\right)$ recipients. Donor $\mathrm{CD} 4$ and $\mathrm{CD} 8$ cells were evaluated in the recipient spleen 4 days after cell transfer. The absolute number of CD4 cells from WT donors was reduced 42-fold after anti-CD28 treatment compared with control treatment, while the absolute numbers of CD4 cells from $I F N-\gamma^{-/-}$donors were reduced only 2.6-fold (Figure 8A). This difference in CD4 depletion induced by anti-CD28 $\mathrm{mAb}$ is statistically significant $(P<0.01)$. Similarly, the absolute number of CD8 cells from WT donors was reduced 66-fold after anti-CD28 treatment, while the absolute numbers of CD8 cells from $I F N-\gamma^{-1-}$ donors were reduced only 4.7-fold (Figure 8A). This difference in CD8 depletion is also statistically significant $(P<0.01)$. These results indicate that IFN- $\gamma$ is critically important for $\mathrm{T}$ cell depletion by anti-CD28 mAb.

Since $I F N-\gamma^{-/-}$T cells were largely resistant to depletion by antiCD28 treatment in vivo, we hypothesized that anti-CD28 mAb would not prevent GVHD induced by $\mathrm{T}$ cells from IFN- $\gamma$-deficient donors. Lethal, acute GVHD was readily induced in B10.BR recipients by $\mathrm{T}$ cells from $I F N-\gamma^{-/}$donors. While treatment with anti-CD28 mAb significantly improved long-term survival in the recipients of WT donor cells $(P<0.0001)$, this treatment failed to do so in the recipients of $I F N-\gamma^{-/}$donor cells (Figure 8B). These results demonstrated that IFN- $\gamma$ is necessary for induction of tolerance by anti-CD28 mAb.

\section{Discussion}

In this study, we have found that administration of anti-CD28 mAb amplified activation-dependent production of cytokines in response
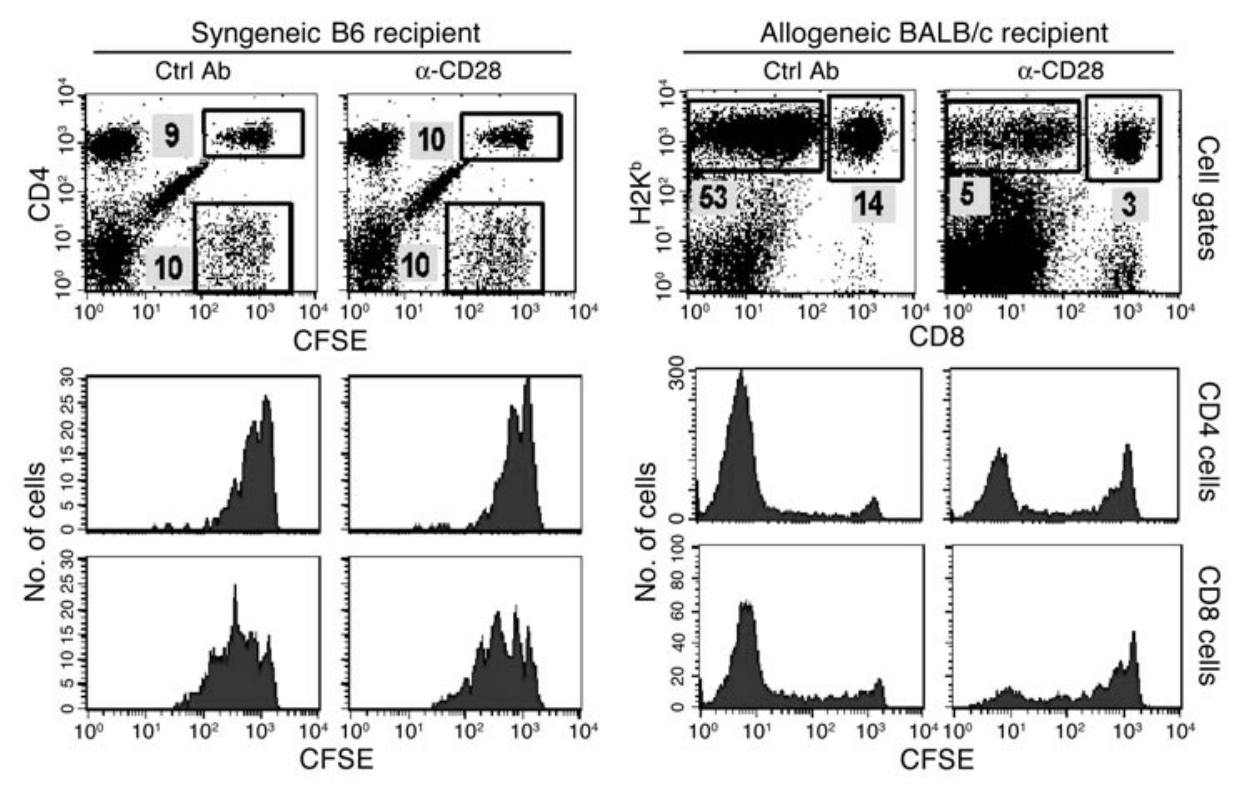

\section{Figure 5}

Anti-CD28 mAb treatment depletes both $\mathrm{CD}^{+}$and $\mathrm{CD}^{+}$cells that recognize alloantigens. CFSE-labeled purified Thy $1.2^{+}$cells from B6 donors were transplanted into irradiated $\mathrm{B} 6$ or $B A L B / c$ recipients. Two groups of three recipients were treated with control or anti-CD28 mAb. At 88 hours after the transplant, pooled splenocytes were stained for expression of surface molecules indicated. $\mathrm{CD}^{+}$and $\mathrm{CD}^{+}$donor cells were identified as $\mathrm{CD}^{+} / \mathrm{CFSE}^{+}$ and $\mathrm{CD}^{-} / \mathrm{CFSE}^{+}$cells in $\mathrm{B} 6$ recipients, respectively. $\mathrm{CD}^{+}$and $\mathrm{CD}^{+}$donor cells were identified as $\mathrm{CD} 8^{-} / \mathrm{H}_{2} \mathrm{~K}^{\mathrm{b}+}$ and $\mathrm{CD}^{+} / \mathrm{H}_{2} \mathrm{~K}^{\mathrm{b}+}$ cells in BALB/c recipients, respectively. The numbers shown are the percentages of donor cells in the individual gate. Lower panels show the CSFE profile on gated $\mathrm{CD}^{+}$and $\mathrm{CD} 8^{+}$donor cells. Results represent one of three replicate experiments. Ctrl, control. 

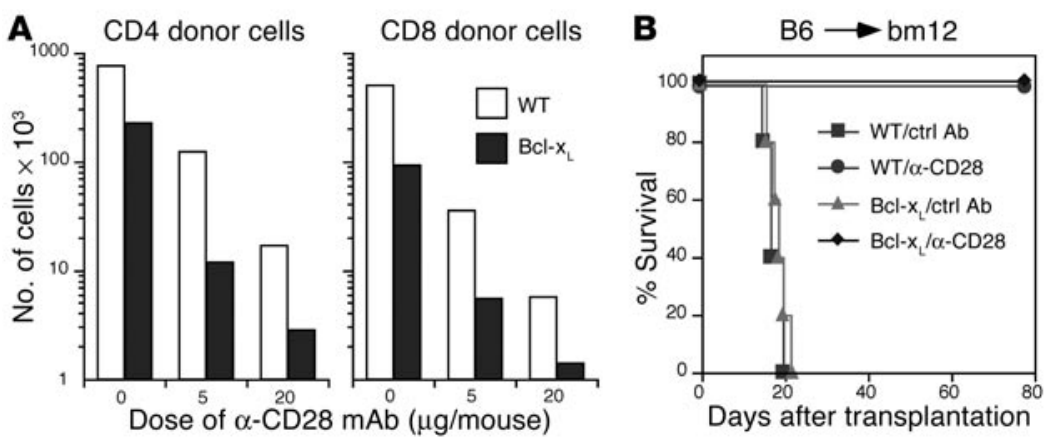

\section{Figure 6}

$\mathrm{Bcl}-\mathrm{X}_{\mathrm{L}}$ does not interfere with the effects of anti-CD28 treatment. (A) Thy $1.2^{+}$cells from $\mathrm{B} 6 \mathrm{WT}$ or $\mathrm{Bcl}-\mathrm{x}_{\mathrm{L}}$ transgenic donors were transplanted into irradiated $\mathrm{BALB} / \mathrm{c}$ recipients. Groups of three mice each were treated with control or anti-CD28 mAb. At 84 hours after the transplant, pooled splenocytes were stained for expression of CD4, CD8, and $\mathrm{H}-2 \mathrm{~K}^{\mathrm{d}}$. The absolute numbers of $\mathrm{CD}^{+}$and $\mathrm{CD}^{+}$donor $\mathrm{T}$ cells in the recipient spleen were calculated from the total number of splenocytes multiplied by the percentage of $\mathrm{CD}^{+} / \mathrm{H}-2 \mathrm{~K}^{\mathrm{d}-}$ and $\mathrm{CD} 8^{+} / \mathrm{H}-2 \mathrm{~K}^{\mathrm{d}-}$ cells in the total spleen population. (B) Purified $\mathrm{CD} 4^{+}$ T cells from WT or Bcl- $x_{L}$ transgenic $B 6$ donors were injected into irradiated (700 cGy) bm12 mice. Recipients were given a single injection of hamster IgG or anti-CD28 mAb at $100 \mu \mathrm{g} /$ mouse on the day of transplantation. Irradiated bm12 mice that received no cells were used as controls without GVHD. Five mice were used in each group.

to specific antigen in vivo. Furthermore, anti-CD28 mAb increased IL-2 production by nontransgenic T cells in response to superantigen in mice that are deficient for the CD28 ligands, CD80/CD86. These results unequivocally show that anti-CD28 functions as an agonistic $\mathrm{mAb}$ in vivo, as it does in vitro. Anti-CD28 therapy depleted CD4 and CD8 $\mathrm{T}$ cells that replicated in response to alloantigen through apoptosis and prevented GVHD. T cell depletion mediated by anti$\mathrm{CD} 28 \mathrm{mAb}$ requires intact IFN- $\gamma$ expression on donor $\mathrm{T}$ cells, but cannot be prevented by overexpression of $\mathrm{Bcl}-\mathrm{x}_{\mathrm{L}}$, and occurs independently of Fas and TNF receptor expression. These results indicate that agonistic Ab's specific for CD28 may be used as novel therapeutic agents to abrogate pathogenic $\mathrm{T}$ cell responses by selecting depletion of activated T cells.

Prenatal blockade of CD80/CD86 substantially inhibits clonal deletion of $\mathrm{T}$ cells in the thymus and leads to an accumulation of autoreactive $\mathrm{T}$ cells in the periphery (28). Using pregnancy as a model, Vacchio and Hodes tested the H-Y specific response of maternal T cells in the presence or absence of CD28 in vivo. They found that peripheral tolerance did not occur in CD28 KO pregnant mice in contrast to the partial clonal deletion and hyporesponsiveness of remaining T cells observed in CD28 WT pregnant mice (17). We recently reported that CD28 costimulation reduces peripheral $\mathrm{T}$ cell responses by increasing apoptosis when TCR ligation exceeds a critical threshold (16). These studies provide evidence that CD28 can contribute to $\mathrm{T}$ cell negative selection in thymic and peripheral $\mathrm{T}$ cells. Here we have provided evidence that engagement with an agonistic anti-CD28 mAb depletes dividing $\mathrm{T}$ cells that recognize alloantigens in vivo but had no detectable effects on donor $\mathrm{T}$ cells transplanted into syngeneic recipients where alloantigen is absent. This finding provides a rationale for the potential application of anti-CD28 therapy to induce antigen-specific T cell tolerance.

There are two leading hypotheses to explain the outcomes of anti-CD28 treatment: inducing $\mathrm{T}$ cell death or blocking $\mathrm{T}$ cell proliferation. We favor the first explanation for the following reasons: (a) treatment with anti-CD28 mAb did not reduce the number of cell divisions (Figures 4 and 5) but increased apoptosis of cells $\mathrm{Bcl}-\mathrm{x}_{\mathrm{L}}$ or other $\mathrm{Bcl}-2$ family members promote $\mathrm{T}$ cell survival under more physiological CD28 stimulation.

Two major pathways account for the death of activated $T$ cells in vivo. One pathway is mediated by death receptors, termed AICD, and the other pathway is regulated by $\mathrm{Bcl}-2$ family proteins, termed activated $\mathrm{T}$ cell autonomous death $(32,33)$. While Fas signaling contributes to the death of some activated $T$ cells, it certainly does not control the death of all activated $T$ cells in vivo, since several reports have shown that activated T cells die in the absence of Fas as well (34-37). By using triple mutant mice deficient for Fas and TNF receptors, we found that these receptors are not required for death of activated T cells after CD28 engagement in vivo. These results also suggest that IFN- $\gamma$-dependent $\mathrm{T}$ cell apoptosis may not necessarily require death receptors.

IFN- $\gamma$ plays a critical role in the regulation of $\mathrm{T}$ cell responses to alloantigens and in the induction of transplant tolerance $(26,27)$. IFN- $\gamma$ is not always necessary for $\mathrm{T}$ cell tolerance, however, because

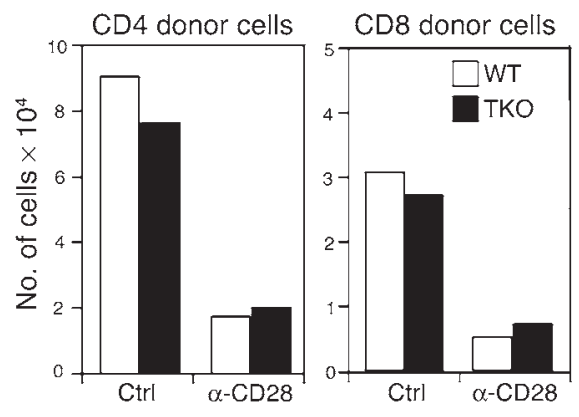

Figure 7

T cells deficient for Fas and TNF receptors are susceptible to antiCD28-induced depletion in vivo. The experiment was conducted as described in Figure 6A. Thy $1.2^{+}$cells from B6 WT or Ipr, p55-/-, and $p 75^{-/-}$triple knock-out (TKO) donors were transplanted into irradiated $\mathrm{BALB} / \mathrm{c}$ recipients. The absolute numbers of $\mathrm{CD}^{+}$and $\mathrm{CD} 8^{+}$donor $\mathrm{T}$ cells are shown. The data represent two replicate experiments. 

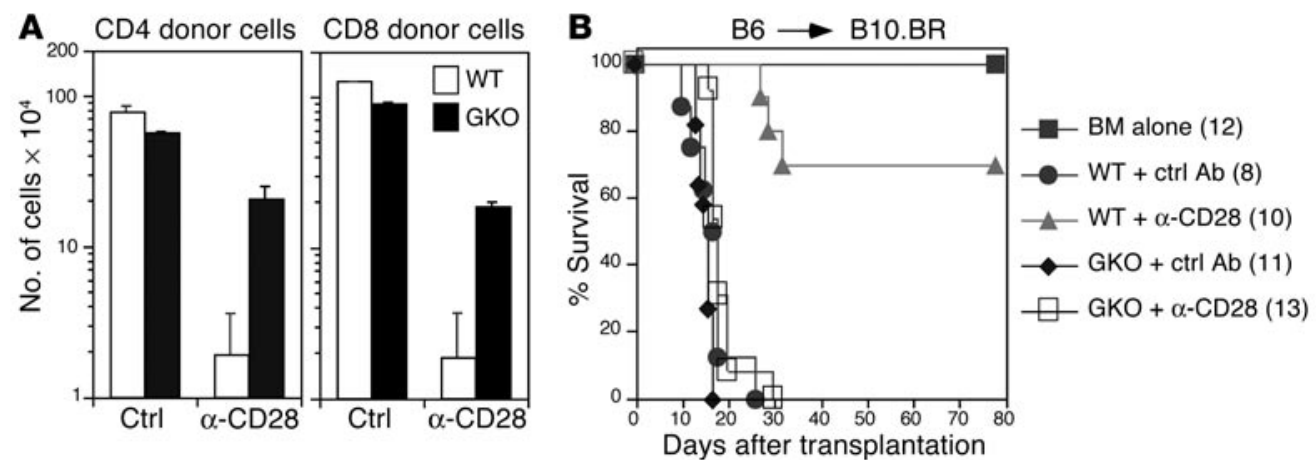

\section{Figure 8}

The role of IFN- $\gamma$ on T cell depletion and GVHD prevention mediated by anti-CD28 mAb. (A) Splenocytes from B6 WT or IFN- $\gamma^{-1-}$ (GKO) donors were transplanted into lethally irradiated B10.BR recipients. Groups of two mice each were treated with control or anti-CD28 mAb at $50 \mu \mathrm{g} /$ mouse. Four days after the cell transfer, spleen cells were stained for expression of CD4, CD8, and $\mathrm{H}-2 \mathrm{~K}^{\mathrm{b}}$. The absolute numbers of CD4+ and $\mathrm{CD}^{+}$donor T cells in the recipient spleen were calculated from the total number of splenocytes multiplied by the percentage of $\mathrm{CD}^{+} / \mathrm{H}_{-}-2 \mathrm{~K}^{\mathrm{b}+}$ and $\mathrm{CD} 8^{+} / \mathrm{H}-2 \mathrm{~K}^{\mathrm{b}+}$ cells in the total spleen population. The data shown are the mean \pm SD from two mice per group and represent two replicate experiments. (B) T cell-depleted marrow cells plus splenocytes from either WT or IFN- $\gamma^{-/-}$B6 donors were injected into lethally irradiated B10.BR recipients. Recipients were given a single injection of hamster IgG or anti-CD28 mAb at $100 \mu \mathrm{g} / \mathrm{mouse}$ on the day of transplantation. Irradiated B10.BR mice that received T cell-depleted marrow cells alone were used as controls without GVHD. The numbers of recipients in each group are shown in the parentheses, and data were pooled from two experiments.

tolerance can be achieved in the absence of IFN- $\gamma$ by anti-LFA-1 therapy in MHC-mismatched transplantation (38) and by blockade of costimulatory signals in minor antigen mismatched transplantation (27). In this report, we showed that IFN- $\gamma$ is required for the depletion of alloreactive $\mathrm{T}$ cells and for the induction of tolerance after CD28 ligation. Interestingly, the induction of tolerance by blocking costimulation also depends on IFN- $\gamma(26,27)$. Blockade of costimulation induces tolerance through passive $\mathrm{T}$ cell apoptosis (29), while CD28 ligation induces tolerance through active T cell apoptosis. Since $\mathrm{T}$ cell apoptosis plays a critical role in transplant tolerance (39, 40 ), it is plausible that IFN- $\gamma$ may be essential for T cell apoptosis and thus required for tolerance induction in multiple systems.

The mechanisms by which IFN- $\gamma$ potentiates death of activated $\mathrm{T}$ cells are largely unknown. Some studies suggested that IFN- $\gamma$ is involved in Fas-mediated apoptosis by promoting caspase- 8 production $(25,41,42)$, while others indicate that activate macrophages and nitric oxide, but not Fas, are required for the IFN- $\gamma$-dependent pathway of apoptosis $(23,43)$. The molecular mechanism(s) by which IFN- $\gamma$ influences $\mathrm{T}$ cell apoptosis after CD28 ligation in vivo are currently under investigation. We propose that agonistic CD28 ligation will deliver signals by way of its cytoplasmic motifs, enhance IFN- $\gamma$ and its inducible genes, activate proapoptotic proteins, and promote death of antigen-activated $\mathrm{T}$ cells through the mitochondrial pathway. Defining the proximal, downstream, and effector signaling pathway(s) by which the agonistic CD28 signal induces negative selection of peripheral $\mathrm{T}$ cells in vivo will likely provide a rationale to selectively target this molecule for in vivo immune modulation.

\section{Methods}

Mice. B6, B6.SJL-Ly5 $5^{a}$ Ptprc ${ }^{a}$ Pep3 ${ }^{b}$ (B6.Ly5.1), BALB/c, B10.BR, $\mathrm{BALB} / \mathrm{c}$ CD28-deficient, and B6 CD80/CD86 double-deficient mice were purchased from The Jackson Laboratory (Bar Harbor, Maine, USA). Founders of DO11.10 transgenic mice were provided by Dennis Y. Loh (Nippon Roche Research Center, Kamakurshi, Japan). The DO11.10 transgenic TCR recognizes a peptide derived from chicken OVA $\left(\mathrm{OVA}_{323-339}\right)$ presented by I-A ${ }^{\mathrm{d}}$. OVA $324-334$ was used as a control peptide. DO11.10 CD28-deficient mice were generated by intercrossing DO11.10 and BALB/c CD28-deficient strains. Bcl- $\mathrm{x}_{\mathrm{L}}$ transgenic founders on a $\mathrm{B} 6$ background were provided by Craig Thompson (University of Pennsylvania, Philadelphia, Pennsylvania, USA). B6 founders deficient for Fas, TNF p55 receptors, and 75 receptors were provided by David Lynch (Amgen Inc., Seattle, Washington, USA). Mice were housed in microisolator cages at the Fred Hutchinson Cancer Research Center (Seattle, Washington, USA). Experimental procedures were reviewed and approved by the Institutional Animal Care and Use Committee.

$R$ Nase protection assay. Total RNA was isolated from the spleens of DO11.10 WT or CD28-deficient mice previously injected with the reagents indicated. Control or OVA peptide was administered at 50 $\mu \mathrm{g} / \mathrm{mouse}$ and control or anti-CD28 mAb at $100 \mu \mathrm{g} / \mathrm{mouse}$. Total RNA was extracted from each spleen using kits from Stratagene (La Jolla, California, USA), according to instructions of the manufacturer. RNase protection assay (RPA) was performed with the RiboQuant Multi-Probe RPA System from PharMingen (San Diego, California, USA). Murine cytokine cDNAs were used as templates for T7 polymerase-directed synthesis of ${ }^{32} \mathrm{P}-\mathrm{UTP}$-labeled antisense RNA probes. A 5- $\mu$ g aliquot of each target RNA was used for hybridization.

T cell purification and transplantation. $\mathrm{CD}^{+}, \mathrm{CD}^{+}$, and Thy $1.2^{+} \mathrm{T}$ cells were purified by positive selection with a magnetic cell separation system (Miltenyi Biotech, Auburn, California, USA), as described previously $(9,20)$. The purity of T cells used in this study ranged from 95 to $99 \%$. In B6 $\left(\mathrm{H}_{2}^{\mathrm{b}}\right) \rightarrow \mathrm{bm} 12\left(\mathrm{H} 2^{\mathrm{bm} 12}\right)$ transplant model, purified $\mathrm{CD}^{+}$cells $\left(10^{5} /\right.$ mouse) from $\mathrm{B} 6 \mathrm{WT}$ or $\mathrm{Bcl}-\mathrm{x}_{\mathrm{L}}$ transgenic donors were injected in the tail vein of irradiated (700 cGy) bm12 recipients. In $\mathrm{B} 6\left(\mathrm{H} 2^{\mathrm{b}}\right) \rightarrow \mathrm{B} 10 . \mathrm{BR}\left(\mathrm{H} 2^{\mathrm{k}}\right)$ transplant model, T cell-depleted marrow cells plus spleen cells from B6 donors (each at $15 \times 10^{6} /$ mouse) were transferred into lethally irradiated (1,000-1,200 cGy) B10.BR (H2 $\left.{ }^{\mathrm{k}}\right)$ recipients. For measurement of proliferative responses in vivo, purified donor T cells were labeled with CFSE (Molecular Probes Inc., Eugene, Oregon, USA) and transferred via the tail vein into previously irradiated $(1,000 \mathrm{cGy}) \mathrm{B} 6\left(\mathrm{H} 2^{\mathrm{b}}\right), \mathrm{BALB} / \mathrm{c}\left(\mathrm{H} 2^{\mathrm{d}}\right)$, or B10.BR $\left(\mathrm{H} 2^{\mathrm{k}}\right)$ recipients. The number of donor cells injected varied among experiments $\left(8 \times 10^{6}\right.$ to $12 \times 10^{6} /$ mouse $)$, but in any given experiment equal numbers of cells were transplanted into each recipient. 
Immunofluorescence analysis. Spleens were harvested and pooled from two or three recipients in each group. Three- or four-color cell staining was performed to measure the expression of surface or intracellular molecules according to standard techniques. Analysis was performed by using a FACScan or FACScalibur and CellQuest software (Becton Dickinson Immunocytometry Systems, San Jose, California, USA). Ab's used for staining included FITC-labeled anti-TCR V $\beta 3$, anti-TCR V $\beta 11$, CyChrome-labeled anti-CD4, APClabeled anti-CD8 $\alpha$, phycoerythrin-labeled (PE-labeled) annexin $\mathrm{V}$, anti-H2 $\mathrm{K}^{\mathrm{d}}$, biotin-labeled anti-IL-2, biotin-labeled anti-H2 $\mathrm{K}^{\mathrm{b}}$, streptavidin-PE and streptavidin-CyChrome (all from PharMingen), and biotin-labeled anti-Ly5.1 prepared in our laboratory.

Statistical analysis. For comparison of recipient survival among groups in GVHD experiments, the log-rank test was used to detect statistical difference. To compare the engraftment, expansion, or depletion of donor T cells in the recipient, a Student's $t$ test was used to detect the statistical difference.

\section{Acknowledgments}

We thank Sasha Mayer, Margaret Castor, and Patty Trobridge for technical assistance. This work was supported by NIH grants CA84132 (to X.-Z. Yu) and CA-18029 and AI-51693 (to C. Anasetti). M.H. Albert is a recipient of a Dr.-Mildred-Scheel fellowship from Deutsche Krebshilfe (German Cancer Aid).

Received for publication December 29, 2003, and accepted in revised form March 23, 2004.

Address correspondence to: Xue-Zhong Yu, Fred Hutchinson Cancer Research Center, D2-100, 1100 Fairview Avenue North, Seattle, Washington 98109, USA. Phone: (206) 667-5988; Fax: (206) 6675255; E-mail: xyu@fhcrc.org.

Claudio Anasetti's present address is: H. Lee Moffitt Cancer Center $\&$ Research Institute, Tampa, Florida 33612, USA.
1. Jenkins, M.K., and Schwartz, R.H. 1987. Antigen presentation by chemically modified splenocytes induces antigen-specific $T$ cell unresponsiveness in vitro and in vivo. J. Exp. Med. 165:302-319.

2. Harding, F.A., McArthur, J.G., Gross, J.A., Raulet, D.H., and Allison, J.P. 1992. CD28-mediated signalling co-stimulates murine $\mathrm{T}$ cells and prevents induction of anergy in T-cell clones. Nature. 356:607-609.

3. Tan, P., et al. 1993. Induction of alloantigen-specific hyporesponsiveness in human $\mathrm{T}$ lymphocytes by blocking interaction of CD28 with its natural ligand B7/BB1. J. Exp. Med. 177:165-173.

4. Lindstein, T., June, C.H., Ledbetter, J.A., Stella, G., and Thompson, C.B. 1989. Regulation of lymphokine messenger RNA stability by a surface-mediated T cell activation pathway. Science. 244:339-343.

5. Boise, L.H., et al. 1995. CD28 costimulation can promote $\mathrm{T}$ cell survival by enhancing the expression of Bcl-XL. Immunity. 3:87-98.

6. Viola, A., Schroeder, S., Sakakibara, Y., and Lanzavecchia, A. 1999. T lymphocyte costimulation mediated by reorganization of membrane microdomains. Science. 283:680-682.

7. Viola, A., and Lanzavecchia, A. 1996. T cell activation determined by $\mathrm{T}$ cell receptor number and tunable thresholds. Science 273:104-106.

8. Iezzi, G., Karjalainen, K., and Lanzavecchia, A. 1998. The duration of antigenic stimulation determines the fate of naive and effector $\mathrm{T}$ cells. Immunity. 8:89-95.

9. Yu, X.Z., Martin, P.J., and Anasetti, C. 1998. Role of CD28 in acute graft-versus-host disease. Blood. 92:2963-2970.

10. Blazar, B.R., Taylor, P.A., Panoskaltsis-Mortari, A., Sharpe, A.H., and Vallera, D.A. 1999. Opposing roles of CD28:B7 and CTLA-4:B7 pathways in regulating in vivo alloresponses in murine recipients of MHC disparate T cells. J. Immunol. 162:6368-6377.

11. Boussiotis, V.A., Lee, B.J., Freeman, G.J., Gribben, J.G., and Nadler, L.M. 1997. Induction of T cell clonal anergy results in resistance, whereas CD28mediated costimulation primes for susceptibility to Fas- and Bax-mediated programmed cell death. J. Immunol. 159:3156-3167.

12. Rajagopalan, G., Smart, M.K., Marietta, E.V., and David, C.S. 2002. Staphylococcal enterotoxin $\mathrm{B}$-induced activation and concomitant resistance to cell death in CD28-deficient HLA-DQ8 transgenic mice. Int. Immunol. 14:801-812.

13. Kaneko, H., et al. 1996. Preferential elimination of CD28+ T cells in systemic lupus erythematosus (SLE) and the relation with activation-induced apoptosis. Clin. Exp. Immunol. 106:218-229.

14. Schirmer, M., Vallejo, A.N., Weyand, C.M., and
Goronzy, J.J. 1998. Resistance to apoptosis and elevated expression of Bcl-2 in clonally expanded CD4+CD28- T cells from rheumatoid arthritis patients. J. Immunol. 161:1018-1025.

15. Markovic-Plese, S., Cortese, I., Wandinger, K.P., McFarland, H.F., and Martin, R. 2001. CD4 ${ }^{+} \mathrm{CD} 28$ costimulation-independent $\mathrm{T}$ cells in multiple sclerosis. J. Clin. Invest. 108:1185-1194. doi:10.1172/ JCI200112516.

16. Yu, X.Z., Martin, P.J., and Anasetti, C. 2003. CD28 signal enhances apoptosis of CD8 T cells after strong TCR ligation. J. Immunol. 170:3002-3006.

17. Vacchio, M.S., and Hodes, R.J. 2003. CD28 costimulation is required for in vivo induction of peripheral tolerance in CD8 T cells. J. Exp. Med. 197:19-26.

18. Krummel, M.F., Sullivan, T.J., and Allison, J.P. 1995. Superantigen responses and co-stimulation: CD28 and CTLA4 have opposing effects on T cell expression in vitro and in vivo. Int. Immunol. 8:519-526.

19. Perez, V.L., et al. 1997. Induction of peripheral T cell tolerance in vivo requires CTLA-4 engagement. Immunity. 6:411-417.

20. Yu, X.Z., Bidwell, S.J., Martin, P.J., and Anasetti, C. 2000. CD28-specific antibody prevents graft-versushost disease in mice. J. Immunol. 164:4564-4568.

21. Dengler, T.J., et al. 1999. Prolonged allograft survival but no tolerance induction by modulating CD28 antibody JJ319 after high-responder rat heart transplantation. Transplantation. 67:392-398.

22. Hill, G.R., et al. 2000. The p55 TNF-alpha receptor plays a critical role in $\mathrm{T}$ cell alloreactivity. J. Immunol. 164:656-663.

23. Dalton, D.K., Haynes, L., Chu, C.Q., Swain, S.L., and Wittmer, S. 2000. Interferon gamma eliminates responding CD4 $\mathrm{T}$ cells during mycobacterial infection by inducing apoptosis of activated CD4 T cells. J. Exp. Med. 192:117-122.

24. Badovinac, V.P., Tvinnereim, A.R., and Harty, J.T. 2000. Regulation of antigen-specific CD8+ T cell homeostasis by perforin and interferon-gamma. Science. 290:1354-1358.

25. Refaeli, Y., Van Parijs, L., Alexander, S.I., and Abbas, A.K. 2002. Interferon gamma is required for activation-induced death of T lymphocytes. J. Exp. Med. 196:999-1005.

26. Konieczny, B.T., et al. 1998. IFN-gamma is critical for long-term allograft survival induced by blocking the CD28 and CD40 ligand T cell costimulation pathways. J. Immunol. 160:2059-2064.

27. Kishimoto, K., et al. 2002. Th1 cytokines, programmed cell death, and alloreactive $\mathrm{T}$ cell clone size in transplant tolerance. J. Clin. Invest. 109:1471-1479. doi:10.1172/JCI200214947.

28. Gao, J.-X., et al. 2002. Perinatal blockage of B7-1 and
B7-2 inhibits clonal deletion of highly pathogenic autoreactive T cells. J. Exp. Med. 195:959-971.

29. Wells, A.D., et al. 1999. Requirement for T-cell apoptosis in the induction of peripheral transplantation tolerance. Nat. Med. 5:1303-1307.

30. Strasser, A., Harris, A.W., Huang, D.C., Krammer, P.H., and Cory, S. 1995. Bcl-2 and Fas/APO-1 regulate distinct pathways to lymphocyte apoptosis. EMBO J. 14:6136-6147.

31. Van Parijs, L., Ibraghimov, A., and Abbas, A.K. 1996. The roles of costimulation and Fas in T cell apoptosis and peripheral tolerance. Immunity. 4:321-328.

32. Hildeman, D.A., Zhu, Y., Mitchell, T.C., Kappler, J., and Marrack, P. 2002. Molecular mechanisms of activated $\mathrm{T}$ cell death in vivo. Curr. Opin. Immunol. 14:354-359.

33. Marsden, V.S., and Strasser, A. 2003. Control of apoptosis in the immune system: Bcl-2, BH3-only proteins and more. Annu. Rev. Immunol. 21:71-105.

34. Tucek-Szabo, C.L., Andjelic, S., Lacy, E., Elkon, K.B., and Nikolic-Zugic, J. 1996. Surface T cell Fas receptor/CD95 regulation, in vivo activation, and apoptosis. Activation-induced death can occur without Fas receptor. J. Immunol. 156:192-200.

35. Hildeman, D.A., et al. 1999. Reactive oxygen species regulate activation-induced $\mathrm{T}$ cell apoptosis. Immunity. 10:735-744.

36. Li, X.C., et al. 1999. Induction of allograft tolerance in the absence of Fas-mediated apoptosis. J. Immunol. 163:2500-2507.

37. Hildeman, D.A., et al. 2002. Activated T cell death in vivo mediated by proapoptotic bcl-2 family member bim. Immunity. 16:759-767.

38. Nicolls, M.R., Coulombe, M., Yang, H., Bolwerk, A., and Gill, R.G. 2000. Anti-LFA-1 therapy induces long-term islet allograft acceptance in the absence of IFN-gamma or IL-4. J. Immunol. 164:3627-3634.

39. Li, X.C., Strom, T.B., Turka, L.A., and Wells, A.D. 2001. T cell death and transplantation tolerance. Immunity. 14:407-416.

40. Zheng, X.X., et al. 2003. Favorably tipping the balance between cytopathic and regulatory $\mathrm{T}$ cells to create transplantation tolerance. Immunity. 19:503-514.

41. Yang, Y.G., Dey, B.R., Sergio, J.J., Pearson, D.A., and Sykes, M. 1998. Donor-derived interferon gamma is required for inhibition of acute graft-versus-host disease by interleukin 12. J. Clin. Invest. 102:2126-2135.

42. Reddy, P., et al. 2001. Interleukin-18 regulates acute graft-versus-host disease by enhancing Fas-mediated donor T cell apoptosis. J. Exp. Med. 194:1433-1440.

43. Sun, Y., et al. 2002. Administration of agonistic anti-4-1BB monoclonal antibody leads to the amelioration of experimental autoimmune encephalomyelitis. J. Immunol. 168:1457-1465. 